This item was submitted to Loughborough's Research Repository by the author.

Items in Figshare are protected by copyright, with all rights reserved, unless otherwise indicated.

\title{
Distribution of agency across body and self
}

PLEASE CITE THE PUBLISHED VERSION

https://global.oup.com/academic/product/distributed-agency-9780190457211

\section{PUBLISHER}

(c) Oxford University Press

\section{VERSION}

AM (Accepted Manuscript)

\section{PUBLISHER STATEMENT}

This work is made available according to the conditions of the Creative Commons Attribution-NonCommercialNoDerivatives 4.0 International (CC BY-NC-ND 4.0) licence. Full details of this licence are available at: https://creativecommons.org/licenses/by-nc-nd/4.0/

\section{LICENCE}

CC BY-NC-ND 4.0

\section{REPOSITORY RECORD}

Parry, Ruth. 2019. "Distribution of Agency Across Body and Self". figshare. https://hdl.handle.net/2134/34403. 


\title{
Chapter 13
}

\section{Distribution of Agency across Body and Self}

\author{
Ruth Parry
}

\section{Introduction}

Many chapters in this book have examined distribution and attribution of agency across multiples of people, or people and artifacts. Here though, I look at attribution of agency within persons: how agency, and thus flexibility and accountability, can be distributed across body — or body parts — and self. To do so, I draw on a corpus of video recordings of physical therapy treatment sessions, supplemented with brief examples from recordings made in other settings — so as to illustrate that the phenomena I examine are not peculiar to physical therapy.

I demonstrate that people can construct three broad configurations:

1. The body (or body part) and the self are constructed as agents separate to one another, disaggregated, capable of "independently: acting one upon the other.

2. The self and body (or body part) are constructed as connected: with the self possessing the body or body part and having an associated control, flexibility, and accountability for bodily actions.

3. The self and body are constructed as one and the same entity and agent: an integrated, accountable, flexible individual. 
I describe the seemingly innocuous and subtle interactional practices we use to construct these quite radically different embodiments/identities (Kockelman 2007a). I will show that we can do so in reference to our own self, or to other persons. The practices describe and illustrate comprise the following:

- Ways that body parts get referred to: whether, for example, we refer to the thumb, or to your or my thumb.

- What we put in the subject and object position of our utterances: for example, whether I say that $I$ do something, or that my leg does something.

- $\quad$ Eye gaze - through which we can show ourselves to be talking to a part of our interlocutor's body—and thus separating it out from a larger whole. Conversely, we can show that we are talking to the "inner" or whole person by looking him or her in the eye.

- $\quad$ Meanings (i.e., semantics) and metaphors that provide for different configurations of the person, body, and self.

It's worth briefly mentioning that the first practice is available in English but not in all languages - although it seems likely that in different languages, other practices are available to do the same kind of work. It is also worth noticing that these configurations have a dualist character, something I will consider as I go along.

As well as describing how people manage to construct different body/self configurations, I examine when and why they do so. In the context of this book, it should come as no surprise that this has to do with how humans attribute and convey capacity and responsibility for their actions, failings, and endeavors. In a final section, I outline 
some implications for how we understand and conceptualize distributed agency, and consider how the dualist character of personhood so prevalent in our talk makes sense in social terms. That is, whatever the material discoveries of neuropsychology, and their echoes in linguistic understandings of inalienable possession (Kockelman 2007b), I am going to show you that when we talk and interact with one another, we do and we can make self and body more, less, or completely—for all practical purposes—separate.

First though, I need to attend to two terminology issues. Frustratingly for me, English does not currently provide a word that signifies, exclusively, the particular part or aspect of a person that is other than the person's body. Soul might once have been used, but has lost some of its value in the context of current understandings that brain, consciousness, and body are utterly intertwined in physical terms. In this piece though, I need to refer to this non-body aspect of a person, and to do so I use self. Also, rather than the body or body part(s), hereon I use the shorthand body/part.

\section{Configuring Body and Self as Unified, or as More or Less Separate}

To put flesh on the bones of the three broad configurations, I examine a series of cases drawn from a much larger set. What I say about the practices and their patterning and functioning in these individual cases reflects analysis of 66 sequences of interaction, nearly all of which involved more than one, often many more than one reference to body/part. Forty-five cases were drawn from a dataset of 86 hours of video-recorded physiotherapy treatment sessions, and 25 were collected from other recordings and transcripts of everyday conversations and also other healthcare interactions. All 
transcripts presented here are simplified versions of the more detailed transcripts created during analysis.

\section{CASE 1: "KEEPING YOU IN THAT POSITION"}

In this example, a therapist and a patient who is receiving rehabilitation for a stroke are talking about a particular goal of his therapy: getting his back and pelvis area more flexible. In the course of this, the therapist describes the physical problem:

Parry PD DT1_2.35

$1 \mathrm{~T}$ : And what's happening is your pelvis is tilting

2 forwards. So it's keeping you in that position.

3 and then you're quite rounded $\mathrm{h}[\mathrm{ere}$ a]t the shoulders

$4 \mathrm{P}$ :

$[\mathrm{Mmm}]$

Using everyday, mundane language resources, the therapist moves rapidly and seamlessly (lines 1-2) from (a) referring to your pelvis with its implication of a possessive connection between patient's self and body, to (b) formulating the pelvis as a separate agent that is keeping the self of the patient in a particular posture. The second formulation entails referring to the pelvis with the impersonal pronoun $i t$, and doing so in the subject position, with you — the self/patient, in the object position. This subject/object arrangement works to convey the pelvis as an agent, and the self/patient as being acted upon by it. In other words, the therapist constructs a part of the patient's body as a discrete, separate agent that acts upon the self of the patient.

As she continues her description (line 3), the therapist uses different means to separate or distance the self of the patient and his pelvis. The subject/object arrangement 
is different, the patient-you—is now the subject and thus agent over the shoulders. The distancing here is done through the pronoun the. In extracts to follow, I will demonstrate and examine how people recurrently use impersonals such as the, this, or $a$ when naming a body part, and the way that this distances the body part from the self.

Why do people talk in ways that distance, disaggregate a self and their body (or body parts)? Recurrently, as above, they do so when referring to something that is a problem — an undesirable physical state or movement. By talking in a way that makes the body part a separate agent acting on the self, or in a way that avoids using possessives such as my or your, one can camouflage the connection—sometimes referred to as "inalienable possession"- - between the person whose physical state is referred to and his or her body/part. One thereby implies that the person neither controls, nor bears accountability, fault, and responsibility for the undesirable bodily state or action. One can sever, so to speak, the connection — physically as much as psychologically.

The next case once again illustrates use of the rather than your, and also introduces another way people can do this disaggregation: through their gaze patterning.

\section{CASE 2: "Always The SlOW ONE"}

A patient and therapist have been working together on a balance exercise in which the patient kneels up on a mat, trying to keep herself upright with straight hips and bottom tucked in. The patient repeatedly sinks back and down because of hip weakness. The therapist is kneeling behind the patient and encouraging her to keep upright by squeezing her buttock muscles (as in line 1). As the patient begins to sink downward once again (line 3), the therapist says "go on, an again, this one 
especially there" while touching and tapping on the patient's right hip and buttock — urging the patient to straighten up, and in particular to do so by using her right buttock and hip.

Parry PD GT1_26.49

$1 \mathrm{~T}$ : That's better. Go on squeeze squeeze lovely,

$2 \quad(4.4)$

$3 \mathrm{~T}$ : Good. Go on an again this one

4 especially. There ((gazing to P's hips))

$5 \quad$ (1.5) ((T taps on P's right hip, P continues to attempt

to keep upright, then shifts body position leaning towards front of $\mathrm{P})$ )

6 T: This right one's always the- ((gazing to P's face))

$7 \mathrm{P}: \quad$ This [one yes the sl]ow one

$8 \mathrm{~T}: \quad$ [the slow one.]

$9 \mathrm{~T}: \quad$ Yea[h]

10 P: [This one is] (like) the slow one

$11 \mathrm{~T}$ : Now see whether you can find your balance.

When giving instructions (lines 1 and 3-4), the therapist looks to the back of the patient's hips. She moves on to give a reason for her "this one especially" instruction (lines 6-7). By the time she starts this talk about a reason, she has shifted her body enough to allow her direct her gaze to the patient's face and make eye contact. Through this patterning, the therapist treats the patient's body and self as separate agents: the body as agent of the 
physical action, and the self—or consciousness—as an agent with regard to hearing and understanding a reason for the action. This gaze patterning is recurrent in the physical therapy data (Parry 2013), with therapists using their gaze and associated body positioning in a way that disaggregates patients' body parts from their reasoning mindstheir selves. As noted, this case also features use of an impersonal pronoun: the therapist talks of this right one, not your right one (line 6). This brings us neatly to case 3, in which an impersonal pronoun the, and the personal pronoun your, are used in rapid succession.

\section{CASE 3: THE THUMB YOUR THUMB}

This patient's traumatic brain injury has left him with difficulties controlling his left side. The therapist here has been moving and stretching his affected left hand and thumb. As we join the session, the therapist asks the patient to try to shake her hand with his left hand.

Parry PD KT3_9.15

$1 \mathrm{~T}$ : C'you shake my hand?

$2 \quad(3.7)$

$3 \mathrm{~T}$ : Pleased to meet you ((jokey tone))

$4=$ uh huh huh heh huh

$5 \quad(0.9)((\mathrm{P}$ lets go of T hand $))$

$6 \mathrm{~T}$ : Now

$7 \quad(0.4)$

$8 \mathrm{~T}$ : 'S not bad 
$10 \mathrm{~T}$ : 'Part from, part from the thumb it's fine Andrew

$11 \quad$ (.)

$12 \mathrm{~T}$ : And can you take your hand away from my hand.

$13 \quad(1.9)$

$14 \mathrm{~T}$ : See if you can try again but making more

$15 \mathrm{~T}$ : of a space for your thumb.

$16 \quad(2.4)$

17 T: Yeah. That's- that feels- that feels better to me.

$18 \mathrm{P}$ : I got the thumb splint.

$19 \quad(0.7)$

$20 \mathrm{~T}$ : Yeah, and whe- how long are you wearing that for.

The therapist says the thumb (line 10) when your thumb would be equally grammatical, and when it is perfectly clear which of his two thumbs she is referring to. As in the other cases, she does this when referring to a physical shortcoming. The thumb is, for all practical purposes, conveyed as a separate entity at this point: the patient's self and thumb are disaggregated, and this reduces the implication that he is responsible or accountable for the physical failure being talked of. This case also illustrates a counterpart: when she moves into instructions the therapist says, can you take your hand away and [make] more of a space for your thumb. By using your at this juncture, she foregrounds the patient's connection with — in other words, his control over - his hand and thumb. So now, the thumb is portrayed as under the patient's control. 
In the physical therapy recordings, both therapists and patients frequently use possessives in situations where controlled, purposeful action is talked about and/or encouraged. Using your or my (when alternatives are possible) treats self and body as connected, and people do so when there is good reason to emphasize someone's control, responsibility, and physical agency in relation to their body.

The rapidity with which one can move between different configurations of the body/self/person relationship is particularly evident in this case, as is the fact that in doing so, a speaker does not need to do anything extra as it were- one does not need to provide talk that, for instance, cancels out an earlier meaning or gives some reason for the change.

\section{CASE 4: IT COLLAPSED; YOU WERE CONTROLLED}

This final case from physical therapy illustrates particularly clearly how people use different body/self configurations to convey just who or what is responsible for a physical success or a physical failure. The patient, whose stroke has resulted in left-sided weakness, is standing with feet slightly apart. The therapist is encouraging her to shift her weight from one foot to the other. A key point of the exercise is for the patient to try to keep her weaker left leg and knee straight as she shifts her weight to this weaker left side.

Parry PD QT2_20.17

$1 \mathrm{~T}$ : Okay that's- that was better that time

2 because the first time it just kind

3 of collapsed ((smiley, gentle tone))

$4 \quad(0.9)$ 
$5 \mathrm{~T}$ : That time you were more controlled.

$6 \quad(0.2)$

$7 \mathrm{~T}$ : Now, as you come back over towards me I want you to ...

At line 2, the therapist's it refers to the patient's left knee and leg. Her talk ascribes this as the entity that collapsed. When she describes the recent successful controlled performance of the exercise, the patient and her body are construed as a single unified agent you. The therapist is thereby able to praise the patient and treat her as responsible for the success.

A series of shorter cases now supplement the detailed analysis above by demonstrating that not just therapists but also patients construct different body/self configurations via the same resources; also that the same kind of phenomena arise in other healthcare settings and in informal conversations between friends.

\section{CASE 5: MY BRAIN DOESN'T TRUST THE LEFT SIDE}

Near the start of a treatment session, a patient who suffered a stroke two weeks previously talks to a therapist about his difficulty in standing up from a sitting position:

Parry Doc HT3_17.03

1 P: $\quad$ Still my brain doesn't trust? the- the er

2 t[he le]ft er [tha]t's why- that's why

$3 \mathrm{~T}: \quad$ [yeah] [yeah]

4 P: $\quad$ every time I stand up? I-I put most of

5 the- my weight on my le-=on my right. 
$7 \mathrm{P}: \quad$ Because my brain doesn't trust the left side

Here the patient makes my brain the subject of his talk, and his left side the object. This subject/object arrangement has parallels to case 1, in which the therapist's talk constructed the patient's pelvis as an agent that was making the patient rounded. There are differences though: rather than self and body part, the patient disaggregates two body parts: brain and left side. Nevertheless, it is reasonable to hear him treating my brain as in some sense his controlling self, and the left side as separate to this brain/self.

\section{CASE 6: I'Ve GOT A FOOT}

This case is from a different healthcare setting: a consultation with a primary care doctor. The extract comes from the start of a consultation.

Robinson and Heritage 2005 page 487: Extract 11: lines 1-5 (simplified)

1 DOC: What you up to?

$2($.

3 PAT: I've gotta bad foot that I can't- get well.

4 (0.2) ((Doc moves his chair close to foot))

5 DOC: Which part.

Here, the patient uses both an impersonal pronoun, $a$, and a verb phrase that I can't get well. These work to disaggregate her self, as an agent, from her foot—upon which she has been attempting to act. 


\section{CASE 7: THOSE BIG TOENAILS}

With this case, we move to everyday conversations. Two friends, Emma and Lottie, are talking on the telephone. We join the conversation as Emma describes, in dramatic terms, a fungal infection affecting her toenails.

NB IV:10R (original transcript line 1472-6) (simplified)

1 Emma: Oḥ God it's terrible Lottie my toenails

2 they're jis look so sick those big toenails it jis

3 u-makes me sick. Yihknow they're disss (.) u-dea:d.

4 Everything's dead I d- I sat out (.) tịhday en

$5 \quad$ I said my God em I jis (.) DYING it's (.) like

$6 \quad$ I'm ossified.

Emma switches from the personal my toenails (line 1), to the impersonal those (line 2) in the context of escalating from "terrible" to nauseating. She also moves from describing a situation-it's terrible — to conveying what she sees as she looks at those big toenails. The impersonal pronoun those adds to the conveyed sense of an external view. By line 6 , she reaches a further configuration: her whole self is conveyed as ossified.

\section{CASE 8: PhysicAlly, NOT MENTALly}

Another everyday conversation case comes from a telephone call between friends. Ava has called Bee, and at the point we enter the call, Bee has been checking with Ava where she is calling from.

TG Ava and Bee, page 15 Line 09 (simplified) 
1 Bee: I finally said something right. (0.2)

2 You are home. Hmm

3 Ava: Yeh- I believe so. [Physically anyway

4 Bee: $\quad[\mathrm{mmh}$

5 Ava: Yea -a-h Not mentally though ((smiley, slightly laughing voice))

Within a jokey exchange, Ava makes a dualist claim—spacially separating her mental and physical self via semantic resources (the meanings of her words) as opposed to the grammatical or gaze resources we saw above.

CASE 9: MY BODY DIDN’T NEED IT

Similarly, in this next case, we see semantics in use to configure the physical body and self as separate.

SN-4_05_lines 01-06 (simplified)

1 Sher: Hi Carol

2 Carol: $\underline{\mathrm{H}[\mathrm{i}]}$

3 Ruth: [Caro]l, Hi

4 Sher: You didn't get an icecream sandwich,

5 Carol: I know, I decided that my body didn't need it

6 Sher: Yes but ours did heh-heh-heh 


\section{CASE 10: SOMETHING BEHIND HER}

This final case comes from a telephone conversation between friends Marsha and Erma. Erma is describing her son's girlfriend Ilene:

MDE:MTRAC:60-1:5 (simplified)

1 Erma: Cause she's gotta very pretty face she ez gorgeous

2 blue eyes, and she really pays very little attention

3 to it and I kind'v am not suprized when Joey says

4 that she wants to go into Social Services, she

5 seems like that kind. Y'know w't I mean she seems

$6 \quad$ like she has a lot (.) there's something behind her.

Erma builds a sense of connection but also a distinction between the inner, private Ilene (behind her-line 6) and Ilene's physical aspect—gorgeous eyes, and a pretty face. This sense is built both through the design of her description - Ilene has physical attributes, and the semantic and metaphoric use of prepositions to indicate this character of selfhood.

\section{Conclusions}

People can allocate to the body, or parts thereof, agency that is more or less separate from the agency of the self. In our social lives at least, while the body and self can be a unified and fused entity, the body and self can also be disaggregated, fissioned, divided. That is, in our interactions, we commit to a form of dualism. This is not a strict "here is body, there is mind" type of dualism, but rather a continuum that can be cut in a variety of 
places. We commit to this form of dualism as a way of understanding ourselves, our personhood. This enables us to manipulate — to shape - the meaning of our own, and other people's physical successes, failures, and features.

As I have shown above, these kinds of allocation of agency are accomplished via rather basic design features of body movement and talk, including gaze, and grammatical and semantic resources. Through the meanings we thereby build, we can encourage others to hear matters of fault, responsibility, endeavor, and achievement with regard the physical as more or less attributable to the body or body part, or to the "true," "inner" self (the soul, or even the brain). It is noticeable that the more distancing configurations are noticeably charitable - we might even say compassionate; the person talking can absolve the person/self being talked about. Being able to allocate responsibility and even blame for physical problems to the body (and therefore as less—or even not at all—the actual person's fault) helps us to limit negative emotional and relationship consequences of criticizing or blaming another's physical state or behavior. Conversely, being able to convey that positive performances and attributes are integral to the person him- or herself allows us to emphasize that person's personal competence, and thus praise, motivate, and encourage him or her, facilitating alignment in terms of both local actions and the ongoing sense of relationship between the people involved.

My analysis has shown that people locally constitute agency and relations between selves and bodies in a moment to moment way that is fitted to social circumstances and also highly flexible. Previous research that has shown that the way one refers to another person is not random; rather, it does work - it performs social actionssuch as conveying another person as more or less close to the speaker (Enfield and 
Stivers 2007; Stivers 2007). My analysis shows that the way we refer to our bodies and our selves is also not a random or haphazard matter, but a socially shaped means of working up distinct embodied identities fitted to interpersonal circumstances and relationships. Finally, the evidence I have presented shows that in order to understand fully the distribution of agency, we need not only to recognize the ways and means through which it can be distributed, fissioned, and fused "across and among individuals" (Enfield 2013:104), but also to add the recognition that people also distribute agency within individuals.

\section{References}

Enfield, N. 2013. Relationship Thinking: Enchrony, Agency, and Human Sociality. New York: Oxford University Press.

Enfield, N. J., and T. Stivers. 2007. Person Reference in Interaction: Linguistic, Cultural, and Social Perspectives. Cambridge: Cambridge University Press.

Kockelman, P., 2007a. “Agency.” Current Anthropology 48(3): 375-401.

Kockelman, P. 2007b. “Inalienable Possession and Personhood in a Q'eqchi'-Mayan Community." Language in Society 36(3): 343-369.

Parry, R. 2013. "Giving Reasons for Doing Something Now or at Some Other Time.” Research on Language \& Social Interaction 46(2): 105-124.

Stivers, T. 2007. “Alternative Recognitionals in Person Reference.” In Person Reference in Interaction - Linguistic, Cultural and Social Perspectives, edited by N. Enfield and T. Stivers, 73-96. Cambridge: Cambridge University Press. 